\title{
Biological Evaluation of 3-Aminoisoquinolin-1(2H)-one Derivatives as Potential Anticancer agents
}

\author{
Lyudmyla M. Potikha ${ }^{\mathrm{a}^{*}}$, Volodymyr S. Brovarets ${ }^{\mathrm{b}}$, Victor V. Zhirnov \\ a Department of Chemistry, Taras Shevchenko National University of Kyiv, \\ Volodymyrska Street, 64/13, Kyiv 01601, Ukraine \\ ${ }^{\mathrm{b}}$ V. P. Kukhar Institute of Bioorganic Chemistry and Petrochemistry of the NAS of Ukraine, \\ 1 Murmanska St., Kyiv, 02094, Ukraine \\ potikha.l.m@gmail.com
}

Keywords: 1-isoquinolinone, anticancer activity, growth inhibitor, cytostatic activity, selectivity. Anticancer activity of a series of 3-(hetaryl/aryl)amino substituted isoquinolin-1(2H)-ones has been studied within the international scientific program "NCI-60 Human Tumor Cell Lines Screen". Screening was performed in vitro on 60 cell lines of lungs, kidneys, CNS, ovaries, prostate, and breast cancer, epithelial cancer, leukemia, and melanoma. The most effective compounds were those with thiazolyl or pyrazolyl substituent at 3-amino group and had no substituents at $\mathrm{C}(4)$ of the isoquinoline cycle. We identified a new lead compound, 3-(1,3-thiazol-2-ylamino)isoquinolin-1(2H)-one 12, which effectively prevents tumor cell growth (average $\lg \mathrm{GI}_{50}=-5.18, \lg \mathrm{TGI}=-4.1, \lg \mathrm{LC}_{50}>-4.0$ ) with good selectivity.

\section{Introduction}

Cancer is one of the main worldwide public health concerns. According to the World Cancer Report published by the World Health Organization in 2020, cancer is one of the leading causes of premature death [1]. The number of people that are diagnoses with cancer every year in Europe will increase from the current 3.5 million to more than 4.3 million by 2035. Therefore, there is an urgent need to pay much attention to update and modify leading drugs in terms of medicinal chemistry and drug design in order to provide more potent and effective therapies. One of the ways to solve this problem is to use the hybrid drugs design strategy which tries to find solutions for undesired properties of the current drug such as drug resistance, drug-drug interactions, and known side effects, just to mention a few. It also provides hybrid structures that are capable of interacting with multiple targets simultaneously with improved efficacy. In essence, the aim of molecular hybridization is to produce a single chemical entity through combination of two or more distinct pharmacophore subunits present in the structures of two or more known bioactive derivatives. For example, pyrazole and thiazole 
derivatives can be cited as examples of the successful application of this strategy [2-6].
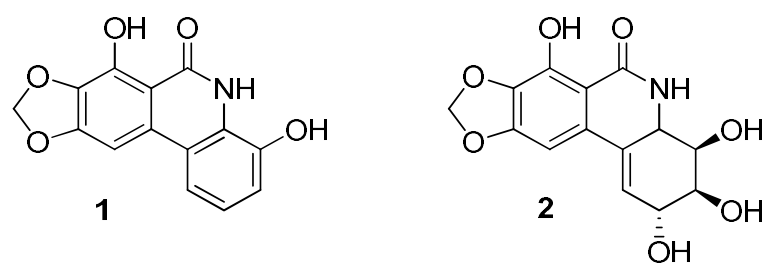

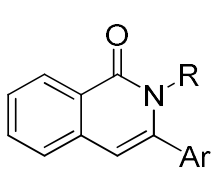

3

$\mathrm{R}=\mathrm{H}, \mathrm{Alk}, \mathrm{Ar}$

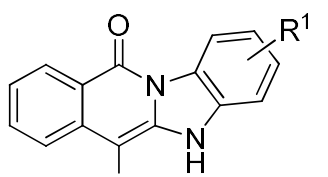

$6 \quad \mathrm{R}^{2} \cdot \mathrm{N}^{-} \mathrm{COR}^{3}$<smiles>[R]c1ccc2c(=O)[nH]c(N)cc2c1</smiles>

$4 \quad \mathrm{R}^{1}$ $\mathrm{R}^{1}=\mathrm{Ar}$, Het, $\mathrm{CH}_{2} \mathrm{Ar}$

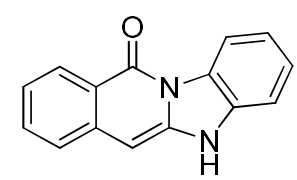

7
Figure 1. Structures of lead anticancer isoquinoline derivatives.

The aim of the current work was to study the anticancer activity of hybrid structures based on isoquinoline. In recent years, the isoquinoline scaffold has gained recognition as a helpful and promising scaffold for the design and development of effective anticancer drugs. Due to distinct and compelling therapeutic properties, natural and synthetic derivatives of isoquinolin$1(2 \mathrm{H})$-one have been widely investigated in medicinal and organic chemistry. One such example is isoquinolinone alkaloids derived from plants of the Amaryllidaceae family narciprimine (1) and narciclasine (2) depicted in Figure 1 [7]. The latter, in the NCI sixty cell line anticancer drug screen exhibited a mean $\mathrm{IC}_{50}$ value of $0.046 \mu \mathrm{M}$ in vitro. 3-Aryl substituted isoquinolinones $(3, \mathrm{R}=\mathrm{H}, \mathrm{Alk})$ displayed diverse anticancer activities against different human cancer cell lines (A549, SK-OV-3, SKMel-2, HCT-15, XF-498) comparable to that of doxorubicin [8]. A series of 2,3-diaryl isoquinolinone derivatives $3(\mathrm{R}=\mathrm{Ar})$ exhibited significant antiproliferative against MCF-7 breast cancer cells and potential antiangiogenesis effects in vivo via $\mathrm{ERa}$ and VEGFR-2 dependent mechanisms [9]. Through review of literature, we found that some phosphatase inhibitors $\left(\mathrm{Cdc} 25 \mathrm{~B}, \quad \mathrm{IC}_{50}=\right.$ $0.77 \div 13.66 \mu \mathrm{M})[10,11]$ with isoquinolin-1-one scaffold bear 3-(hetaryl/aryl)amino or 3benzylamino fragments (4). The method of synthesis of a number of Aurora kinase inhibitors (5) is also based on 3-(pyrazol-3ylamino)-isoquinolin-1(2H)-ones [12]. The strong activity in suppressing proliferation and growth of glioblastoma cells [13], colorectal (SW620, HT29, GI50 = 23.8 $24.13 \mu \mathrm{M})$ [14] and CNS (SF-295, GI = 55\%) [15] human cancer cell lines was found for condensed derivatives having a 3 -aminoisoquinolinone moiety (6). The unsaturated $5 H$-benzo[4,5]imidazo[1,2b]isoquinolin-1-one (7) exhibited significant Cdc25B inhibition $\left(\mathrm{IC}_{50}=5.3 \mu \mathrm{M}\right)[11]$. In this context, the consolidation of the 3aminoisoquinolinone template and novel carbo/heteroaromatic rings as novel pharmacophores seems to be promising for obtaining highly effective anticancer drugs. 


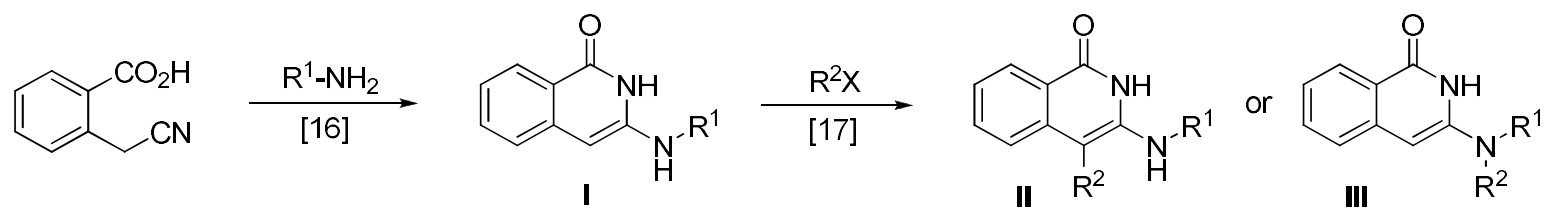

I:<smiles>Cn1cnnc1CNc1cc2ccccc2c(=O)[nH]1</smiles>
NSC 776637<smiles>CCOc1ccc(C(=O)c2c(Nc3ccccn3)[nH]c(=O)c3ccccc23)cc1</smiles><smiles>Cn1nccc1CNc1cc2ccccc2c(=O)[nH]1</smiles>
9<smiles>Cc1cc(Nc2cc3ccccc3c(=O)[nH]2)n(C)n1</smiles><smiles></smiles><smiles>O=c1[nH]c(Nc2nccs2)cc2ccccc12</smiles><smiles>CCOc1ccc(C(=O)c2c(Nc3nccs3)[nH]c(=O)c3ccccc23)cc1</smiles><smiles>CCOc1ccc(C(=O)c2c(Nc3c(C)nn(C)c3C)[nH]c(=O)c3ccccc23)cc1</smiles>

III:<smiles>CCOc1ccc(C(=O)N(c2ccc(F)cc2)c2cc3ccccc3c(=O)[nH]2)cc1</smiles>

Figure 2. General scheme for the synthesis of isoquinolinone derivatives and compounds selected for in vitro testing.

Earlier [16], we have developed a simple and convenient method for the synthesis of 3aminoisoquinolin-1(2H)-ones (I) from 2(cyanomethyl)benzoic acid that made possible the variation of the substituent at the 3 -amino group (Figure 2).

The unique electronic nature of the 3aminoisoquinolinone moiety allowed regiospecific substitution on the enamine moiety of the molecules, such as acylation at either the $\mathrm{C}(4)$ or the $3-\mathrm{N}$ positions [17]. This reaction allowed producing a series of 3(hetaryl/aryl)amino-isoquinolinones and their acyl derivatives (II) and the study of their in vitro antiproliferative activities.

\section{Experimental part}

Chemistry

3-[(Hetarylmethyl)amino]isoquinolin-

1(2H)-ones 8,9 [16] and 3-(hetarylamino)-
isoquinolin-1(2H)-ones $\quad \mathbf{1 0 - 1 2} \quad[16], \quad 4-(4-$ ethoxybenzoyl)-3-(hetarylamino)isoquinolin1(2H)-ones 13-15 [17] and $N$-(4-fluorophenyl)$\mathrm{N}$-(1-oxo-1,2-dihydro-3-isoquinolinyl)-4ethoxybenzamide 16 [17] were synthesized following the procedures described in the corresponding cited sources.

\section{In vitro Anticancer Screening}

In vitro anticancer screening methodology as well as data interpretation rules are described in details at the NCI Development Therapeutics Program site [18].

\section{Results and discussion}

The structures of the 3aminoisoquinolin-1(2H)-ones were submitted to US National Institute of Health, and the nine compounds 8-12 and 13-16 (Figure 2) were selected for evaluation of their antiproliferative activity within an international scientific 
program. These compounds (8-16) were granted NSC codes, viz., NSC $776637 \div$ NSC 776641 , and NSC $776643 \div$ NSC 776646, respectively. The elected compounds were submitted to in vitro anticancer assay against a full panel of 60 cancer cell lines taken from different tissues (lungs, kidneys, CNS, ovaries, prostate, breast cancer, epithelial cancer, leukemia, and melanoma). The compounds were tested at a single dose concentration of $10^{-5} \mathrm{M}$. Growth percentage (GP) of cancer cells compared to the control (in the absence of a chemical substance, $100 \%$ ) was determined [19-22].

Isoquinolinone derivatives 8-16 exhibit different levels of anticancer activity depending on the substituents at the 3-amino group and at C(4) (Table 1). It has been shown that 3hetarylamino derivatives $\mathbf{1 0 - 1 2}$ are the most active against cancer cells in a wide range of cell lines.

The 1,3-thiazol-2-ylamino derivative $\mathbf{1 2}$ was the most potent of all the derivatives tested, with mean GP value of $49.57 \%$ for the majority of cell lines. It showed to be selective towards the breast cancer sub-panel, being active against all the corresponding cell lines. The most sensitive were MDA-MB-468 and MCF7 cell lines with GP $10.72 \%$ and $26.62 \%$, respectively. Other cell lines that showed more than $70 \%$ growth inhibition in the micro molar range were UO-31 (GP 22.78\%) and SK-MEL-5 (GP $22.08 \%$ ) belonging to the renal cancer and melanoma sub-panels respectively. Also, compound 12 showed significant inhibition of most of the leukemia, lung, CNS, renal and breast cancer cell lines with GP less than 50\%. It is worthy to note that the thiazol-2-ylamino derivative 12 showed good selectivity towards the colon, melanoma and ovarian cancer subpanels.

1,3-Dimethyl-1H-pyrazol-5-yl (10) and

$$
\text { 1,3,5-trimethyl- } 1 H \text {-pyrazol-4-yl }
$$

isoquinolinones, unlike the thiazolyl derivative 12, showed higher selectivity level towards cancer cells of all sub-panels, but with higher mean GP value of $59.51 \%$ and $61.68 \%$, respectively. Replacement of the thiazole with pyrazole in compounds $\mathbf{1 0}$ and $\mathbf{1 1}$ maintained the antitumor activity against most of the cell lines of leukemia and breast cancer sub-panels. The most sensitive are RPMI-8226 (leukemia, GP $34.33 \%$ (10) and 28.68\% (11)) and MDA-MB468 (breast cancer, GP 19.94\% (10) and 15.70\% (11)). Pyrazolyl derivatives 10 and 11 showed high effectiveness against ovarian OVCAR-4 cell line with GP values of $30.45 \%$ and $18.20 \%$, respectively. The dimethylpyrazolyl derivative 10 had a lethal effect on renal A498 cell line (GP $-3.00 \%$ ) and inhibited the growth of melanoma SK-MEL-5 cells by more than 70\% (GP $25.26 \%$ ). At the same time, the trimethylpyrazolyl derivative $\mathbf{1 1}$ showed the opposite result: lethal effect on melanoma SKMEL-5 cell line (GP -12.06\%) and GP of $25.60 \%$ against renal A498 cells. In addition, compounds 10 and 11 proved to have a comparable effect on the SF-295 cell line of CNS cancer with GP values of $40.97 \%$ and $40.21 \%$, respectively. 
FRENCH-UKRAINIAN JOURNAL OF CHEMISTRY (2021, VOLUME 09, ISSUE 02)

Table 1. Mitotic activity (GP) of the 3-aminoisoquinolin-1(2H)-one derivatives 8-16 towards NCI 60 cell lines at the $10^{-5} \mathrm{M}$ concentration

\begin{tabular}{|c|c|c|c|c|c|c|c|c|c|}
\hline Cell line name & 8 & 9 & 10 & 11 & 12 & 13 & 14 & 15 & 16 \\
\hline \multicolumn{10}{|c|}{ Leukemia } \\
\hline CCRF-CEM & - & - & 47.31 & 56.48 & 43.13 & - & - & 66.59 & - \\
\hline HL-60(TB) & - & - & 76.26 & - & 48.51 & - & - & - & 51.48 \\
\hline $\mathrm{K}-562$ & - & - & 47.23 & 41.21 & 49.27 & - & - & 52.95 & - \\
\hline MOLT-4 & - & - & 50.93 & 57.97 & 30.19 & 70.00 & - & 41.92 & 70.87 \\
\hline RPMI-8226 & - & - & 34.33 & 28.68 & 30.30 & - & 78.96 & 40.58 & - \\
\hline SR & - & - & 59.37 & 38.72 & 47.84 & - & - & 66.44 & - \\
\hline \multicolumn{10}{|c|}{ Non-Small Cell Lung Cancer } \\
\hline A549/ATCC & - & - & 59.38 & 58.23 & 54.69 & - & - & 68.00 & - \\
\hline HOP-62 & - & - & 64.13 & 65.22 & 49.89 & - & - & - & - \\
\hline NCI-H226 & - & - & 59.51 & 54.54 & 44.97 & - & - & - & - \\
\hline NCI-H23 & - & - & 46.32 & 42.19 & 50.20 & - & - & - & - \\
\hline NCI-H322M & - & - & 79.19 & 78.97 & 57.37 & - & - & - & - \\
\hline NCI-H460 & - & - & 70.47 & 75.59 & 66.98 & - & - & 75.50 & - \\
\hline NCI-H522 & - & - & $\mathrm{nt}$ & 36.21 & 42.28 & 68.59 & 61.18 & 55.16 & 39.68 \\
\hline \multicolumn{10}{|c|}{ Colon Cancer } \\
\hline COLO 205 & - & - & 76.77 & - & 61.01 & - & - & 75.68 & - \\
\hline HCC-2998 & - & - & - & - & 61.42 & - & - & - & - \\
\hline HCT-116 & - & - & 58.56 & 52.17 & 52.60 & - & - & 69.24 & - \\
\hline HCT-15 & - & - & 63.27 & 70.68 & 44.44 & - & - & 74.72 & - \\
\hline HT29 & - & - & $\mathrm{nt}$ & 78.58 & 55.21 & - & - & 71.19 & - \\
\hline KM12 & - & - & 67.91 & 78.19 & 50.48 & - & - & 71.49 & - \\
\hline SW-620 & - & - & - & - & 78.85 & - & - & - & - \\
\hline \multicolumn{10}{|c|}{ CNS Cancer } \\
\hline SF-268 & - & - & 78.96 & 72.71 & 58.62 & - & - & 73.04 & - \\
\hline SF-295 & - & - & 40.97 & 40.21 & 47.57 & - & - & 69.72 & - \\
\hline SF-539 & - & - & 52.13 & 75.91 & 45.07 & - & - & - & - \\
\hline SNB-19 & - & - & - & 69.33 & 45.45 & - & - & 71.05 & - \\
\hline SNB-75 & - & - & 64.51 & 64.44 & 45.61 & 77.98 & - & 70.15 & - \\
\hline $\mathrm{U} 251$ & - & - & 67.79 & 69.53 & 36.12 & - & - & 71.03 & - \\
\hline \multicolumn{10}{|c|}{ Melanoma } \\
\hline LOX IMVI & - & - & 47.20 & 69.35 & 50.88 & - & - & - & - \\
\hline M14 & - & - & 70.38 & 64.78 & 56.36 & - & - & 73.03 & 76.33 \\
\hline MDA-MB-435 & - & - & 68.89 & 61.42 & 48.07 & - & - & 77.36 & - \\
\hline SK-MEL-2 & - & - & $\mathrm{nt}$ & - & 72.60 & - & - & - & - \\
\hline SK-MEL-28 & - & - & - & - & - & - & - & - & - \\
\hline SK-MEL-5 & - & 77.47 & 25.26 & -12.06 & 22.08 & - & - & 42.60 & 79.71 \\
\hline UACC-257 & - & - & 53.52 & 48.81 & 55.00 & - & - & - & - \\
\hline UACC-62 & - & - & 53.99 & 67.76 & 51.34 & 72.56 & - & 65.87 & 64.92 \\
\hline
\end{tabular}


Table 1. (Contd.)

\begin{tabular}{|c|c|c|c|c|c|c|c|c|c|}
\hline Cell line name & 8 & 9 & 10 & 11 & 12 & 13 & 14 & 15 & 16 \\
\hline \multicolumn{10}{|c|}{ Ovarian Cancer } \\
\hline IGROV1 & - & - & 78.16 & 78.49 & 42.80 & - & - & - & - \\
\hline OVCAR-3 & - & - & 58.43 & 50.36 & 33.18 & - & - & 74.84 & - \\
\hline OVCAR-4 & - & - & 30.45 & 18.20 & 40.97 & - & - & 66.05 & - \\
\hline OVCAR-5 & - & - & - & - & - & - & - & - & - \\
\hline OVCAR-8 & - & - & 57.87 & 55.31 & 46.51 & - & - & 61.00 & 70.11 \\
\hline NCI/ADR-RES & - & - & 70.79 & 69.97 & 57.30 & - & - & 64.62 & - \\
\hline SK-OV-3 & - & - & - & - & 52.41 & - & - & - & - \\
\hline \multicolumn{10}{|c|}{ Renal Cancer } \\
\hline 786-0 & - & - & 65.52 & 65.03 & 75.74 & - & - & - & - \\
\hline A498 & - & - & -3.00 & 25.60 & 35.19 & 77.76 & 63.45 & 65.98 & - \\
\hline $\mathrm{ACHN}$ & - & - & 72.93 & 69.95 & 65.46 & - & - & - & - \\
\hline CAKI-1 & - & - & 66.59 & 67.37 & 48.41 & - & - & - & - \\
\hline RXF 393 & - & - & 64.65 & 59.43 & 45.86 & - & - & 65.60 & - \\
\hline SN12C & - & - & 57.25 & 68.09 & 42.49 & - & - & 67.22 & - \\
\hline TK-10 & - & - & $\mathrm{nt}$ & 62.59 & 48.06 & - & - & - & - \\
\hline UO-31 & 77.45 & - & 32.51 & 50.28 & 22.78 & 43.33 & - & 46.51 & 78.76 \\
\hline \multicolumn{10}{|c|}{ Prostate Cancer } \\
\hline PC-3 & - & - & 58.96 & 79.43 & 52.77 & 64.41 & - & 58.19 & - \\
\hline DU-145 & - & - & 71.58 & 66.69 & 68.66 & - & - & 79.83 & - \\
\hline \multicolumn{10}{|c|}{ Breast Cancer } \\
\hline MCF7 & - & 68.83 & 33.10 & 52.14 & 26.62 & 72.31 & 78.93 & 68.12 & - \\
\hline MDA-MB-231/ATCC & - & - & 41.93 & 54.19 & 31.45 & - & - & 66.08 & 77.50 \\
\hline HS 578T & - & - & 71.50 & 75.26 & 61.98 & - & - & 79.63 & - \\
\hline BT-549 & - & - & 46.35 & 41.70 & 36.39 & - & - & 67.39 & - \\
\hline $\mathrm{T}-47 \mathrm{D}$ & - & - & 42.27 & 45.05 & 36.00 & - & - & 66.67 & - \\
\hline MDA-MB-468 & - & 78.74 & 19.94 & 15.70 & 10.72 & 77.42 & 67.73 & 51.97 & - \\
\hline Mean GP & 99.72 & 102.14 & 59.51 & 61.68 & 49.57 & 89.49 & 95.13 & 73.55 & 90.31 \\
\hline
\end{tabular}

-: GP more than $80 \%$, nt: not tested

Replacement of the azolyl fragment with azolylmethyl as in compounds 8 and 9 leads either to a sharp decrease (growth inhibition < $20 \%$ ) or to a complete loss of the antitumor activity (Table 1), which may be attributed to restricted conformation of compounds 8 and 9 on the receptor binding site due to an increase in the spatial volume of the substituent at the 3 -amino group.
A similar effect was noted in an earlier study [11] evaluating the requirements of 3anilinoisoquinolinone scaffold for the inhibition of the in vitro phosphatase activity of recombinant human $\mathrm{Cdc} 25 \mathrm{~B}$. Thus, the retention of a relatively low inhibitory activity of isoquinolinone derivative 9 towards some breast cancer cell lines (MCF7, MDA-MB-468) and melanoma (SK-MEL-5) is probably due to the 
presence of another strong pharmacophore (pyrazolyl fragment) in the molecule.

The unique 'enamine-like' structure of the isoquinolinone core provides an additional area for diversification. Therefore, several compounds (1316) among the readily available 4 -acyl and $3-N$-acyl substituted derivatives of 3-aminoisoquinolinones [17] with an additional pharmacophore $-p$ ethoxybenzoyl fragment - were selected for evaluation of their antiproliferative activity. However, the introduction of a 4-(p-ethoxybenzoyl) substituent proved to be detrimental to the inhibitory activity for all tested compounds, similar to that observed for 3 -[(4methylphenyl)amino]isoquinolinone with an unsubstituted 4-benzoyl group [11]. Preliminary in vitro antitumor screening revealed that unsubstituted 3-[(4-fluorophenyl)amino] and 3-[(4pyridyl)amino] derivatives of isoquinolinone showed good inhibition [11], while their benzoyl derivatives $\mathbf{1 3}$ and $\mathbf{1 6}$ turned out to be inactive for most of the cancer cell lines excepted a few of them. The most sensitive were leukemia HL-60(TB) and lung cancer NCI-H522 cell lines for compound $\mathbf{1 6}$ with GP $51.48 \%$ and $39.68 \%$, respectively. Renal UO-31 cell line was sensi-tive to compound $\mathbf{1 3}$ with GP value of $43.33 \%$.

Benzoylated thiazolyl derivative $\mathbf{1 4}$ is also almost completely inactive against most of the cancer cell lines. The value of its growth inhibition exceeded $30 \%$ in only three cases: lung cancer NCIH522, renal A498 and breast cancer MDA-MB-468 cell lines. Pyrazolyl derivative $\mathbf{1 5}$ displayed the most potent overall antiproliferative activity among the 4-benzoyl derivatives tested, with mean GP value of $73.55 \%$. It exhibited a more than $50 \%$ inhibition for some of the cell lines belonging to different tumor sub-panels: leukemia cells MOLT4 and RPMI-8226 giving GP values of $41.92 \%$, and $40.58 \%$, respectively, melanoma cells SK-MEL-5 with GP a value of $42.60 \%$, and renal cancer cells UO-31 with a GP value of $46.51 \%$.

Among all the 4-benzoyl derivatives tested, the sharpest decrease of the antitumor activity was observed for the thiazolyl derivative $\mathbf{1 4}$ as compared to its unsubstituted analogue 12 , and may be attributed to the presence of two acceptor substituents in the molecule. In the case of compound 14, this leads to deeper changes in the distribution of electron density in the isoquinolinone moiety due to the formation of an ortho-quinone structure favored by an intramolecular hydrogen bond between the 3-imino and 4-enol fragments [17], as shown in Scheme 1.

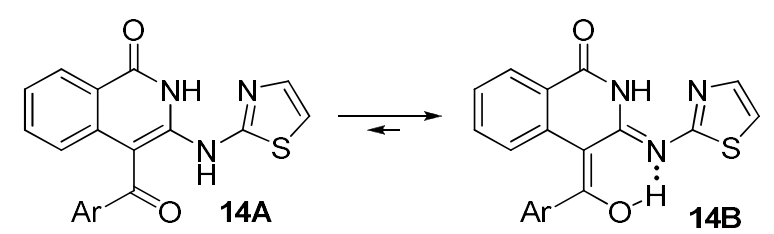

Scheme 1. Tautomeric forms of thiazolyl derivative 14.

Thus, Table $\mathbf{1}$ revealed that compound $\mathbf{1 2}$ is the most active towards numerous cancer cell lines belonging to different tumor sub-panels. Therefore, it was selected in advanced assay against a panel of approximately 60 tumor cell lines at 10-fold dilution of five concentrations $\left(10^{-4}-10^{-8} \mathrm{M}\right)$, the set of which was identical to that for the pre-screening stage (Table 2). The results were compared with 5fluorouracil (5-FU) as reference drug (Table 2), which has been used as a standard for more than 40 years [23, 24]. 
Table 2. Parameter values (lg) of the anticancer activity of compound $\mathbf{1 2}$ and 5-fluorouracil as reference compound against the NCI 60 human cancer cell lines (five-dose assay).

\begin{tabular}{|c|c|c|c|c|c|c|c|}
\hline \multirow{2}{*}{ Cell Line } & \multicolumn{2}{|c|}{12} & \multirow{2}{*}{$\begin{array}{c}\mathbf{5 - F U ^ { \mathrm { a } }} \\
\mathrm{GI}_{50}\end{array}$} & \multirow{2}{*}{ Cell Line } & \multicolumn{2}{|c|}{12} & \multirow{2}{*}{$\begin{array}{c}\mathbf{5}-\mathbf{F} \mathbf{U}^{\mathrm{a}} \\
\mathrm{GI}_{50}\end{array}$} \\
\hline & $\mathrm{GI}_{50}$ & TGI & & & $\mathrm{GI}_{50}$ & TGI & \\
\hline \multicolumn{8}{|c|}{ Leukemia } \\
\hline CCRF-CEM & -5.07 & $>-4.00$ & -5.01 & MOLT-4 & -5.27 & $>-4.00$ & -6.45 \\
\hline HL-60(TB) & -4.82 & $>-4.00$ & -5.60 & SR & -4.98 & $>-4.00$ & -5.01 \\
\hline K-562 & -5.28 & $>-4.00$ & -5.45 & & & & \\
\hline \multicolumn{8}{|c|}{ Non-small cell lung cancer } \\
\hline A549/ATCC & -4.89 & $>-4.00$ & -6.80 & NCI-H23 & -5.30 & $>-4.00$ & -6.75 \\
\hline HOP-62 & -5.48 & -4.19 & -7.28 & NCI-H322M & -5.11 & $>-4.00$ & -6.67 \\
\hline HOP-92 & -5.57 & -5.06 & -6.64 & NCI-H460 & -4.64 & $>-4.00$ & -6.03 \\
\hline NCI-H226 & -5.18 & $>-4.00$ & -6.96 & NCI-H522 & -4.98 & $>-4.00$ & -6.80 \\
\hline \multicolumn{8}{|c|}{ Colon cancer } \\
\hline COLO 205 & -5.09 & $>-4.00$ & -6.80 & HT29 & -4.48 & $>-4.00$ & -6.75 \\
\hline HCC-2998 & -4.63 & $>-4.00$ & -7.28 & KM12 & -5.04 & $>-4.00$ & -6.67 \\
\hline НCТ-116 & -5.16 & $>-4.00$ & -6.64 & SW-620 & -4.42 & $>-4.00$ & -6.03 \\
\hline HCT-15 & -5.39 & $>-4.00$ & -6.96 & & & & \\
\hline \multicolumn{8}{|c|}{ CNS cancer } \\
\hline SF-268 & -5.26 & $>-4.00$ & -5.80 & SNB-19 & -5.29 & $>-4.00$ & -5.42 \\
\hline SF-295 & -5.15 & $>-4.00$ & -6.64 & SNB-75 & -5.69 & -4.97 & -4.10 \\
\hline SF-539 & -5.42 & $>-4.00$ & -7.20 & U251 & -5.41 & -4.12 & -6.04 \\
\hline \multicolumn{8}{|c|}{ Melanoma } \\
\hline LOX IMVI & -5.16 & $>-4.00$ & -6.61 & SK-MEL-28 & -4.80 & $>-4.00$ & -5.99 \\
\hline MALME-3M & $>-4.00$ & $>-4.00$ & -7.29 & SK-MEL-5 & -5.41 & -4.54 & -6.33 \\
\hline M14 & -5.21 & $>-4.00$ & -6.01 & UACC-257 & -4.94 & $>-4.00$ & -5.45 \\
\hline MDA-MB-435 & -5.16 & $>-4.00$ & - & UACC-62 & -5.32 & $>-4.00$ & -6.28 \\
\hline SK-MEL-2 & -4.83 & -4.07 & -4.25 & & & & \\
\hline \multicolumn{8}{|c|}{ Ovarian cancer } \\
\hline IGROV1 & -5.28 & $>-4.00$ & -5.91 & OVCAR-8 & -5.32 & $>-4.00$ & - \\
\hline OVCAR-3 & -5.26 & $>-4.00$ & -7.80 & NCI/ADR-RES & -5.15 & $>-4.00$ & -4.66 \\
\hline OVCAR-5 & -4.01 & $>-4.00$ & -5.76 & SK-OV-3 & -5.29 & $>-4.00$ & -5.91 \\
\hline \multicolumn{8}{|c|}{ Renal cancer } \\
\hline $786-0$ & -4.95 & $>-4.00$ & -6.14 & RXF 393 & -5.57 & -5.00 & -5.58 \\
\hline A498 & -5.85 & -4.63 & -6.40 & SN12C & -5.11 & $>-4.00$ & -6.30 \\
\hline $\mathrm{ACHN}$ & -5.21 & $>-4.00$ & -6.53 & TK-10 & -5.07 & -4.05 & -5.95 \\
\hline CAKI-1 & -5.14 & $>-4.00$ & -7.14 & UO-31 & -5.86 & $>-4.00$ & -5.85 \\
\hline \multicolumn{8}{|c|}{ Prostate cancer } \\
\hline PC-3 & -5.41 & $>-4.00$ & -5.63 & DU-145 & -4.61 & $>-4.00$ & -6.44 \\
\hline \multicolumn{8}{|c|}{ Breast cancer } \\
\hline MCF7 & -5.86 & $>-4.00$ & -7.10 & BT-549 & -5.69 & -4.78 & -4.97 \\
\hline MDA-MB-231/ATCC & -5.79 & -4.17 & -5.18 & T-47D & -5.72 & $>-4.00$ & -5.09 \\
\hline HS 578T & -5.41 & $>-4.00$ & -5.01 & MDA-MB-468 & -5.94 & - & - \\
\hline
\end{tabular}

${ }^{\text {a }}$ Data for 5-fluorouracil are given according to [25] 
The high antitumor potential of compound $\mathbf{1 2}$ has been confirmed by a significant level of inhibition (average $\lg \mathrm{GI}_{50}=$ -5.18) and cytostatic (average $\lg$ TGI $=-4.1$ ) effects for some cell lines. However, the level of cytotoxic effect $\lg \mathrm{LC}_{50}$ of all cell lines was not high and exceeded average value of -4.00 . The cell lines that were the most sensitive to the tested compound 12 were: HOP-92 non-small cell lung $\left(\lg \mathrm{GI}_{50}=-5.57, \lg \mathrm{TGI}=-5.06\right), \mathrm{SNB}-75 \mathrm{CNS}$ $\left(\lg \mathrm{GI}_{50}=-5.69, \lg\right.$ TGI $\left.=-4.97\right)$, A498 renal $(\lg$ $\mathrm{GI}_{50}=-5.85, \lg$ TGI $\left.=-4.63\right)$, RXF 393 renal $(\mathrm{lg}$ $\mathrm{GI}_{50}=-5.57, \lg$ TGI $\left.=-5.00\right)$, MDA-MB231/ATCC breast $\left(\lg \mathrm{GI}_{50}=-5.79, \lg\right.$ TGI $=-$ $4.17)$ and BT-549 breast ( $\lg \mathrm{GI}_{50}=-5.69, \lg$ TGI $=-4.78)$. 3-(Thiazolylamino)isoquinolinone 12 showed the greatest activity against most of the cell lines of the lung, colon, CNS, ovarian, renal and breast cancer sub-panels.

Overall, the activity of 5-fluorouracil (average $\lg \mathrm{GI}_{50}=-6.10$ [25]) is higher than isoquinolinone 12. Nevertheless, compound 12 demonstrates a higher activity than standard 5fluorouracil does against: SNB-75 (CNS); SKMEL-2 (melanoma); NCI/ADR-RES (ovarian); MDA-MB-231/ATCC, HS 578T, BT-549 and T47D (breast). Moreover, compounds 12 and 5fluorouracil proved to have similar efficiency against the renal RXF 393 and UO-31 cell lines. Additionally, compound $\mathbf{1 2}$ demonstrated a remarkable activity towards breast MDA-MB468 with $\lg \mathrm{GI}_{50}$ value of -5.97 .
We have performed COMPARE [26] analyses for the active compound $\mathbf{1 2}$ in order to investigate the similarity of its cytotoxicity pattern with those of known anticancer standard agents, NCI active synthetic and natural compounds, which are present in public available databases [27]. According to the Chaddock scale [28], compound $\mathbf{1 2}$ has a low positive COMPARE correlation of $\mathrm{GI}_{50}$ vector with triciribine phosphate $(\mathrm{r}=0.35)$. Moreover, matrix COMPARE using TGI vector showed moderate positive correlations with triciribine phosphate and spirohydantoin mustard $(r=0.6$ for both) (Figure 3).

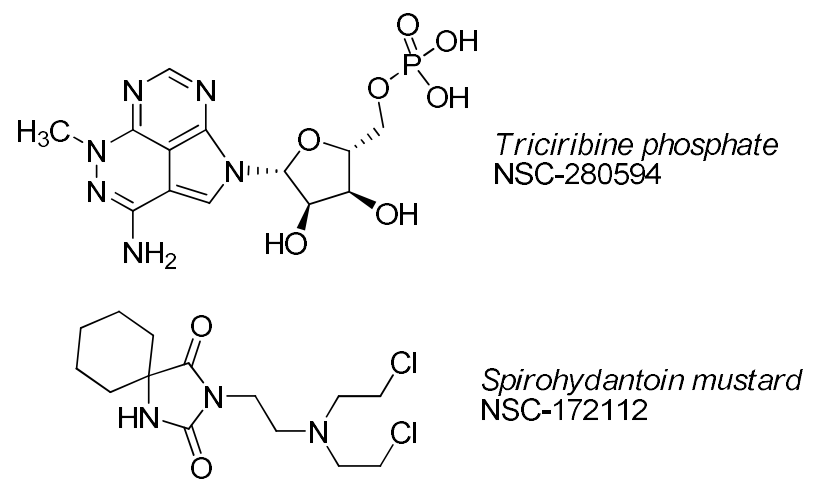

Figure 3. Structures of NCI anticancer standard agents.

The mechanism of action for triciribine (NCS 280594) includes its prevention Protein kinase B (AKT) membrane translocation [29], and specifically its binding to the $\mathrm{PH}$ domain of AKT, thereby blocking its recruitment to the membrane, leading to subsequent inhibition of AKT phosphorylation in tumours [30, 31]. The mechanism of antineoplastic activity of spirohydantoin mustard (NCS 172112), like for all other alkylating agents, lies in its ability to alkylate DNA guanine nucleobases and, thus, to 
prevent uncoupling of DNA strands, which is a required step for any cell to divide [32]. Obviously, the antiproliferative activity of 3(thiazolylamino)isoquinolinone $\mathbf{1 2}$ is not associated with the ability to alkylate DNA guanine nucleobases. Taken together, this suggests that the most likely molecular target for 3-(thiazolylamino)isoquinolinone $\mathbf{1 2}$ is Protein kinase B. However, the absence of a very high positive correlation with the above compounds requires further experimental studies for the correct interpretation of the results obtained.

\section{Conclusions}

Herein we demonstrated the in vitro anticancer activity of some 3(hetaryl/aryl)aminoisoquinolin-1(2H)-ones against the NCI 60 human cancer cell lines. Therein, the nature of the substituent at the $\mathrm{C}(4)$ and 3-N positions of isoquinoline cycle critically affects the level of activity. More favorable is the presence of a thiazolyl or a pyrazolyl substituent at the 3-amino group. In the same time, the presences of acceptor substituents at $\mathrm{C}(4)$ position or at 3-amino group and an increase in the spatial volume of the substituent at the 3amino group are detrimental to the inhibitory activity. Although the critical biochemical targets of 3-hetarylaminoisoquinolin-1(2H)-ones have not been identified, they show an interesting antiproliferative profile against different human tumor-derived cell lines, especially: 3-[(1,3dimethyl-1H-pyrazol-5-yl)amino] and 3-[(1,3,5-
trimethyl-1H-pyrazol-4-yl)amino]isoquinolin1(2H)-ones $\mathbf{1 0}$ and $\mathbf{1 1}$ against RPMI-8226 (leukemia), MDA-MB-468 (breast cancer), OVCAR-4 (ovarian), A498 (renal) and SKMEL-5 (melanoma) cell lines. We identified a new lead compound, 3-(1,3-thiazol-2ylamino)isoquinolin-1(2H)-one $\mathbf{1 2}$, which efficiently prevents tumor cell growth of MDAMB-468 and MDA-MB-231/ATCC (breast cancer), UO-31 and A498 (renal), SNB-75 (CNS) and HOP-92 (non-small cell lung) cell lines. Thus, the 3-aminoisoquinoline series provides an attractive new core structure for additional analysis and optimization.

\section{Acknowledgements}

We would like to thank National Cancer Institute, Bethesda, MD, US for the anticancer activity investigations and Enamine Ltd. for the material and technical support.

\section{References}

[1] Cao B, Soerjomataram I, Bray F. The global cancer burden. In: Wild CP, Weiderpass E, Stewart BW, editors. World Cancer Report: Cancer Research for Cancer Prevention. Lyon, France: International Agency for Research on Cancer; 2020.

[2] Aziz H, Zahoor AF, Ahmad S. Pyrazole bearing molecules as bioactive scaffolds: A review. J Chil Chem Soc. 2020;65(1):4746-4753.

[3] Kumari P, Mishra VS, Narayana C, Khanna A, Chakrabarty A, Sagar R. Design and efficient synthesis of pyrazoline and isoxazole bridged indole $C$-glycoside hybrids as potential anticancer agents. Sci Rep. 2020;10:6660. 
[4] Guerrero-Pepinosa NY, Cardona-Trujillo MC, Garzón-Castaño SC, Veloza LA, Sepúlveda-Arias JC. Antiproliferative activity of thiazole and oxazole derivatives: A systematic review of in vitro and in vivo studies. Biomed Pharmacother. 2021;138:111495.

[5] Alizadeh SR, Hashemi SM. Development and therapeutic potential of 2-aminothiazole derivatives in anticancer drug discovery. Med Chem Res. 2021;30:771806.

[6] Ramos-Inza S, Aydillo C, Sanmartín C, Plano D. Thiazole Moiety: An Interesting Scaffold for Developing New Antitumoral Compounds. In: Nandeshwarappa BP, Sadashiv SO, editors. Heterocycles - Synthesis and Biological Activities. IntechOpen; 2019. p. 1-21.

[7] Habartováa K, Cahlíkováb L, Řezáčová M, Haveleka R. The Biological Activity of Alkaloids from the Amaryllidaceae: From Cholinesterases Inhibition to Anticancer Activity. Nat Prod Commun. 2016;11(10):15871594.

[8] Cheon SH, Park JS, Lee JY, Lee YN, Yi H, Chung B-H, Choi B-G, Cho W-J, Choi S-U, Lee C-O. StructureActivity Relationship Studies of Isoquinolinone Type Anticancer Agent. Arch Pharm Res. 2001;24(4):276-280.

[9] Tang Z, Niu S, Liu F, Lao K, Miao J, Ji J, Wang X, Yan M, Zhang L, You Q, Xiao H, Xiang H. Synthesis and biological evaluation of 2,3-diaryl isoquinolinone derivatives as anti-breast cancer agents targeting ERa and VEGFR-2. Bioorganic Med Chem Lett. 2014;24(9):21292133.

[10] Johnston PA, Foster CA, Tierno MB, Shun TY, Shinde SN, Paquette WD, Brummond KM, Wipf P, Lazo JS. Cdc25B Dual-Specificity Phosphatase Inhibitors Identified in a High-Throughput Screen of the NIH Compound Library. Assay Drug Dev Technol. 2009;7(3):250-265.

[11] Rosenker KMG, Paquette WD, Johnston PA, Sharlow ER, Vogt A, Bakan A, Lazo JS, Wipf P. Synthesis and biological evaluation of 3 -aminoisoquinolin-1(2H)-one based inhibitors of the dual-specificity phosphatase Cdc25B. Bioorganic Med. Chem. Lett. 2015;23(12):28102818 .
[12] Chen L, Georges G, Mertens A, Wu X, inventors; F. Hoff-Mann-La Roche AG, assignee. Isoquinoline aminopyrazole derivatives, their manufacture and use as pharmaceutical agents for the treatment of cancer. World Intellectual Property Organisation patent 2007/071348. 2007 June 28.

[13] Chen H, He L, Li S, Zhang Y, Huang J, Qin H, Wang J, Li Q, Yang D. A Derivate of BenzimidazoleIsoquinolinone Induces SKP2 Transcriptional Inhibition to Exert Anti-Tumor Activity in Glioblastoma Cells. Molecules. 2019;24(15):2722-2734.

[14] He LJ, Yang DL, Li S, Zhang YJ, Tang Y, Lei J, Frett B, Lin HK, Li HY, Chen ZZ, Xu ZG. Facile construction of fused benzimidazole-isoquinolinones that induce cell-cycle arrest and apoptosis in colorectal cancer cells. Bioorg Med Chem. 2018;26(14):3899-3908.

[15] Sondhi SM, Rani R, Singh J, Roy P, Agrawal SK, Saxena AK. Solvent free synthesis, anti-inflammatory and anticancer activity evaluation of tricyclic and tetracyclic benzimidazole derivatives Bioorganic Med Chem Lett. 2010;20(7):2306-2310.

[16] Potikha LM, Gutsul RM, Kovtunenko VA, Tolmachev AA. 3-(Hetarylamino)- and 3[(hetarylmethyl)amino]-isoquinolin-1 $(2 H)$-ones. Chem Heterocycl Comp. 2010;46(4):457-467.

[17] Potikha LM, Gutsul RM, Kovtunenko VA, Turov AV. Study of acylation reactions in 3-aminocarbostyril derivatives. Chem Heterocycl Comp. 2010;46(5):569-580. [18] NCI-60 Human Tumor Cell Lines Screen. DTP Developmental Therapeutics Program, NIH website [Internet]. 2020 [updated 20 March 2020]. Available from:https://dtp.cancer.gov/discovery_development/nci60/default.htm.

[19] Alley MC, Scudiero DS, Monks PA, Hursey ML, Czerwinski MJ, Fine DL, Abbott BJ, Mayo JG, Shoemaker RH, Boyd MR. Feasibility of Drug Screening with Panels of Human Tumor Cell Lines Using a Microculture Tetrazolium Assay. Cancer Res. 1988;48(3):589-601. 
[20] Grever MR, Schepartz SA, Chabner BA. The National Cancer Institute: cancer drug discovery and development program. Semin Oncol. 1992;19(6):622-638.

[21] Boyd MR, Paull KD. Some practical considerations and applications of the national cancer institute in vitro anticancer drug discovery screen. Drug Dev Res. 1995;34(2):91-109.

[22] Shoemaker RH. The NCI60 human tumour cell line anticancer drug screen. Nat Rev Cancer. 2006;6(10):813-823.

[23] Arias JL. Novel Strategies to Improve the Anticancer Action of 5-Fluorouracil by Using Drug Delivery Systems. Molecules. 2008;13(10):2340-2369.

[24] Bunz F. Thymidylate synthase and 5-fluorouracil: a cautionary tale. Cancer Biol Ther. 2008;7(7):995-996.

[25] Luzina EL, Popov AV. Synthesis and anticancer activity of N-bis(trifluoromethyl)alkyl-N'-thiazolyl and Nbis(trifluoromethyl)alkyl-N'-benzothiazolyl ureas. Eur J Med Chem. 2009;44(12):4944-4953.

[26] Paull KD, Shoemaker RH, Hodes L, Monks A, Scudiero DA, Rubinstein L, Plowman J, Boyd MR. Display and analysis of patterns of differential activity of drugs against human tumor cell lines: development of mean graph and COMPARE algorithm. J Natl Cancer Inst. 1989;81(14):1088-1092.

[27] COMPARE Analysis. DTP Developmental Therapeutics Program, NIH website [Internet]. US National Cancer Institute; 2021 [updated 26 February 2021]. Available from: https://dtp.cancer.gov/databases tools/compare.htm.

[28] Mukaka MM. Statistics corner: A guide to appropriate use of correlation coefficient in medical research. Malawi Med J. 2012;24(3):69-71.

[29] Kim D, Sun M, He L, Zhou QH, Chen J, Sun XM, Bepler G, Sebti SM, Cheng JQ. A small molecule inhibits Akt through direct binding to Akt and preventing Akt membrane translocation. J Biol Chem. 2010;285(11):83838394.
[30] Berndt N, Yang H, Trinczek B, Betzi S, Zhang Z, Wu B, Lawrence NJ, Pellecchia M, Schönbrunn E, Cheng JQ, Sebti SM. The Akt activation inhibitor TCN-P inhibits Akt phosphorylation by biding to the $\mathrm{PH}$ domain of Akt and blocking its recruitment to the plasma membrane. Cell Death Differ. 2010;17(11):1795-1804.

[31] Garrett CR, Coppola D, Wenham RM, Cubitt CL, Neuger AM, Frost TJ, Lush RM, Sullivan DM, Cheng JQ, Sebti SM. Phase I pharmacokinetic and pharmacodynamic study of triciribine phosphate monohydrate, a smallmolecule inhibitor of AKT phosphorylation in adult subjects with solid tumor containing activated AKT. Invest New Drugs. 2011;29(6):1381-1389.

[32] Brown TD, Ettinger DS, Donehower RC. A Phase I Trial of Spirohydantoin Mustard (NSC 172112) in Patients With Advanced Cancer. J Clin Oncol. 1986;4(8):1270-1276. 